University of Wollongong

Research Online

Australian Institute for Innovative Materials -

Papers

Australian Institute for Innovative Materials

$1-1-2011$

\title{
A highly ordered titania nanotube array as a supercapacitor electrode
}

\author{
Maryam Salari \\ University of Wollongong, msalari@uow.edu.au \\ Seyed Hamed Aboutalebi \\ University of Wollongong, sha942@uowmail.edu.au \\ Konstantin Konstantinov \\ University of Wollongong, konstan@uow.edu.au \\ Hua-Kun Liu \\ University of Wollongong, hua@uow.edu.au
}

Follow this and additional works at: https://ro.uow.edu.au/aiimpapers

Part of the Engineering Commons, and the Physical Sciences and Mathematics Commons

Research Online is the open access institutional repository for the University of Wollongong. For further information contact the UOW Library: research-pubs@uow.edu.au 


\title{
A highly ordered titania nanotube array as a supercapacitor electrode
}

\begin{abstract}
We report the synthesis of self-organized titania nanotubes and nanocrystalline titania powders employing an alternative and novel approach. Integrating these nanostructures in a binder-free working electrode improved the capacitance up to $911 \mathrm{uF} \mathrm{cm}$, which is around one to two orders of magnitude higher than the conventional electric double layer capacitors.
\end{abstract}

\section{Keywords}

highly, ordered, titania, nanotube, array, supercapacitor, electrode

Disciplines

Engineering | Physical Sciences and Mathematics

\section{Publication Details}

Salari, M, Aboutalebi, S, Konstantinov, KK \& Liu, HK (2011), A highly ordered titania nanotube array as a supercapacitor electrode, Physical Chemistry Chemical Physics, 13(11), pp 5038-5041. 
Cite this: Phys. Chem. Chem. Phys., 2011, 13, 5038-5041

\title{
A highly ordered titania nanotube array as a supercapacitor electrode
}

\author{
Maryam Salari,* Seyed Hamed Aboutalebi, Konstantin Konstantinov and Hua Kun Liu \\ Received 6th October 2010, Accepted 17th January 2011 \\ DOI: $10.1039 / \mathrm{c0cp02054k}$
}

\begin{abstract}
We report the synthesis of self-organized titania nanotubes and nanocrystalline titania powders employing an alternative and novel approach. Integrating these nanostructures in a binder-free working electrode improved the capacitance up to $911 \mu \mathrm{F} \mathrm{cm} \mathbf{c m}^{-2}$, which is around one to two orders of magnitude higher than the conventional electric double layer capacitors.
\end{abstract}

Nanostructured materials are playing an important role in the field of electrochemical capacitors and are receiving remarkable attention, as they offer the combination of the nanoscale dimension with a highly defined geometry and a very high surface area. This may allow, in some cases, for entirely new properties, but in many cases, for the amplification of established properties of materials.

Over the past few decades, titanium dioxide, due to its exceptional characteristics and strikingly high potential for practical applications, has been considered as a hotspot for many applications. ${ }^{1-6}$ Among different methods introduced for the preparation of titania nanotubes, anodic oxidation of titanium foil has been extensively investigated. ${ }^{7-11}$ This method offers suitably back-contacted nanotube layers on the substrate, which can be employed directly as an electrochemical device or a probe. ${ }^{2-4,12}$ Recently, self-organized titania nanotubes have been used as supercapacitor electrode material as an alternative to or co-material with other metal oxides, due to their semiconducting properties, accessible surface, electrochemical behaviour and long-term chemical stability. ${ }^{13-16}$

It is widely believed that bare titania due to high electric resistance and low specific surface area reveals low electrochemical capacitance. In general, titania would resemble conventional electric double layer capacitors which contribute a non-faradic mechanism with a very low specific capacitance of $10-40 \mu \mathrm{F} \mathrm{cm}^{-2}$ in the charge-discharge process. To the best of authors' knowledge, a highly ordered three-dimensional network of $\mathrm{TiO}_{2}$ nanotubes have just been used as a support to fabricate composite electrodes for electrochemical capacitor applications. $^{15,17}$ The present work addresses the electrochemical behaviour of titania nanotubes and nanocrystalline titania powders. These electrochemical properties demonstrate

Institute for Superconducting and Electronic Materials,

ARC Centre for Electromaterials Science, University of Wollongong,

NSW2519Wollongong, Australia.E-mail:ms591@uowmail.edu.au;

Fax: + 61 42215731; Tel: +61242981470 that titania nanotubes have great potential as electrochemical supercapacitor electrodes.

The anodization was conducted on $\mathrm{Ti}$ foil $(99.7 \%$ purity, Sigma) acting as an anode with platinum foil as the cathode. The electrolyte consisted of $0.2 \mathrm{wt} \% \mathrm{NH}_{4} \mathrm{~F}$ dissolved in a mixture of glycerol and de-ionized water ( $9: 1$ in volume). The anodization was performed under a constant voltage of $15 \mathrm{~V}$ for $17 \mathrm{~h}$. After being dried in air, the nanotubes were annealed at temperatures of up to $630{ }^{\circ} \mathrm{C}$ under an argon atmosphere for $2 \mathrm{~h}$.

Nanocrystalline titania powder was synthesised via a sol-gel method employing two-stage hydrolysis of titanium (IV)-isopropoxide (TTIP, Aldrich). De-ionized water (TTIP $/ \mathrm{H}_{2} \mathrm{O}=1 / 20$ ) was added into the diluted solution of TTIP $($ TTIP/ethanol $=1 / 5)$, together with $\mathrm{HCl}(32 \%$, Aldrich $)$ and $\mathrm{NH}_{4} \mathrm{OH}\left(28-30 \% \mathrm{NH}_{3}\right.$ content, Aldrich) catalytic agents. The solution was stirred at room temperature for $1 \mathrm{~h}$. The final white slurry was filtered, dried at $100{ }^{\circ} \mathrm{C}$ overnight, and then annealed at $780{ }^{\circ} \mathrm{C}$ for $1 \mathrm{~h}$.

To investigate the surface morphology and microstructure of $\mathrm{TiO}_{2}$ nanotubes, Field Emission Scanning Electron Microscopy (FE-SEM; JEOL JSM-7500FA), X-ray diffraction (XRD) and Glancing Angle X-ray Diffraction (GAXRD; GBC MMA X-Ray diffractometer with $\mathrm{Cu}-\mathrm{K}_{\alpha}$ radiation) were employed.

The aligned titania nanotubes $\left(\mathrm{TiO}_{2} / \mathrm{NT}\right)$ grown on the surface of the Ti substrate were used directly as the working electrode. In addition, the electrochemical properties of $\mathrm{TiO}_{2} / \mathrm{NT}$ were compared with those of the working electrode made of nanocrystalline $\mathrm{TiO}_{2}$ powder prepared by a conventional slurry method consisting of $70 \mathrm{wt} \%$ of active material.

Electrochemical measurements were performed in $1 \mathrm{M} \mathrm{KCl}$ aqueous solution. A platinum sheet and an $\mathrm{Ag} / \mathrm{AgCl}$ ( $\mathrm{KCl}$ saturated) electrode were used as the counter and reference electrodes, respectively. An electrochemical workstation (CHI660B, CH Instruments, Inc.) consisting of Cyclic Voltammetry (CV) and Electrochemical Impedance Spectroscopy (EIS) was employed to investigate the specific capacitance of the electrodes. CV was conducted over a voltage range of -0.2 to $0.6 \mathrm{~V}$ at various scan rates $\left(1 \mathrm{mV} \mathrm{s}^{-1}\right.$ to $\left.100 \mathrm{mV} \mathrm{s}^{-1}\right)$. EIS measurements were carried out between $100 \mathrm{kHz}$ and $1 \mathrm{~Hz}$ under a constant potential of $-0.1 \mathrm{~V}$ using a $5 \mathrm{mV}$ rms sinusoidal modulation.

Fig. 1a and b show a GAXRD pattern of $\mathrm{TiO}_{2} / \mathrm{NT}$ and a XRD pattern of $\mathrm{TiO}_{2}$ /powder, respectively. Fig. 1a demonstrates that annealing at $630{ }^{\circ} \mathrm{C}$ leads to the formation of a 


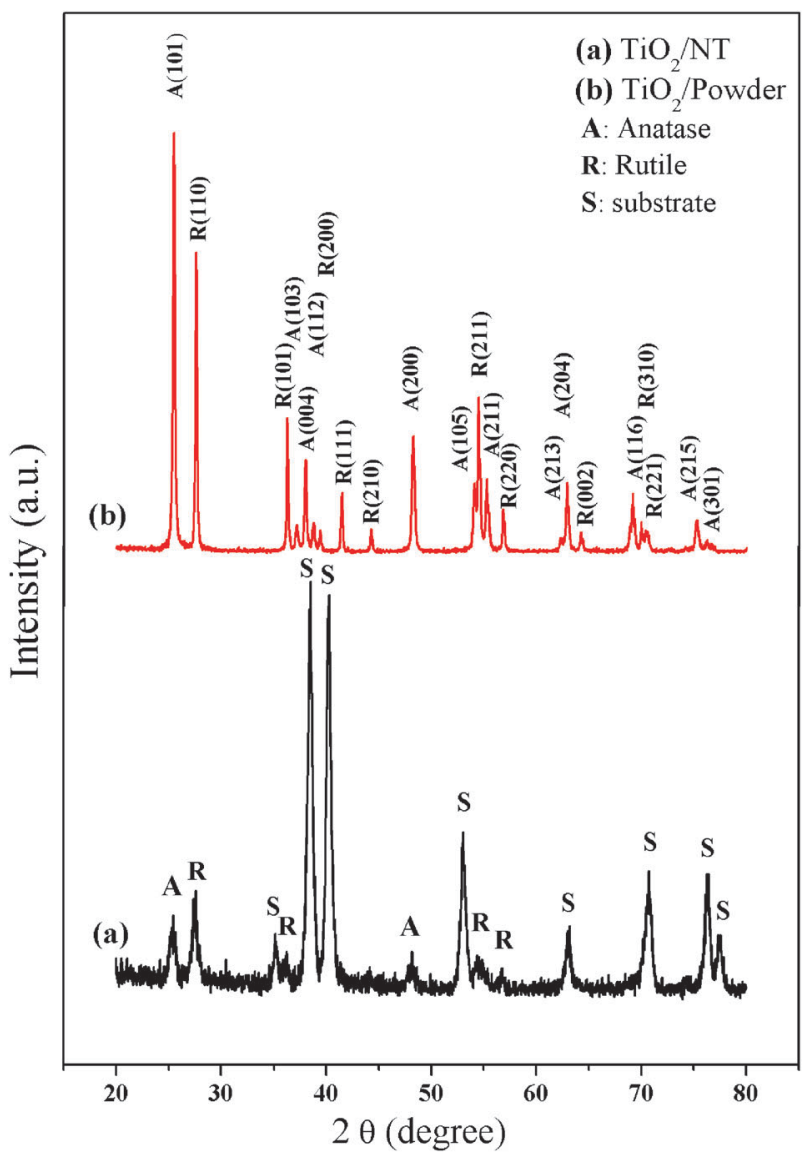

Fig. 1 (a) GAXRD pattern of $\mathrm{TiO}_{2} / \mathrm{NT}$ annealed up to $630^{\circ} \mathrm{C}$ for $2 \mathrm{~h}$ and (b) XRD pattern of $\mathrm{TiO}_{2} /$ powder annealed at $780{ }^{\circ} \mathrm{C}$ for $1 \mathrm{~h}$.

combination of anatase and rutile phases. Fig. $1 \mathrm{~b}$ presents the XRD pattern of nanocrystalline $\mathrm{TiO}_{2}$ powder. The average crystallite sizes of anatase and rutile phases of the powder were calculated, using Scherrer's equation, to be 45 and $64 \mathrm{~nm}$, respectively. The relative weight percentage of the anatase phase was also calculated from the Spurr and Myers equation ${ }^{18}$ to be $37 \%$ and $53 \%$ for $\mathrm{TiO}_{2} / \mathrm{NT}$ and nanocrystalline $\mathrm{TiO}_{2}$ powder, respectively.

Fig. 2a-c shows the side and top views of FE-SEM micrographs of $\mathrm{TiO}_{2}$ nanotubes $\left(\mathrm{TiO}_{2} / \mathrm{NT}\right)$ synthesized by anodic oxidation. The average inner diameter, wall thickness and length of the $\mathrm{TiO}_{2}$ nanotubes measured from FE-SEM images

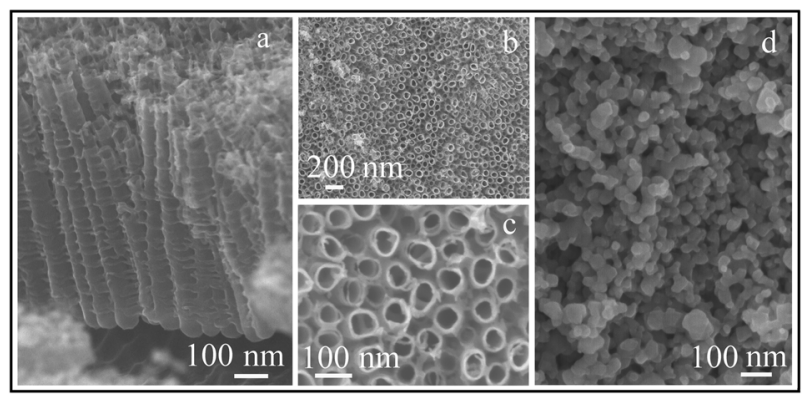

Fig. 2 (a) Side view, (b) top view, (c) high magnification top view FE-SEM images of $\mathrm{TiO}_{2} / \mathrm{NT}$ prepared by anodic oxidation and (d) FE-SEM image of nanocrystalline $\mathrm{TiO}_{2} /$ powder prepared by the sol-gel method. are approximately $40-60 \mathrm{~nm}, 10-20 \mathrm{~nm}$ and $900-1000 \mathrm{~nm}$, respectively. As it can be seen in Fig. 2a, titania nanotubes are ordered and vertically aligned on the $\mathrm{Ti}$ substrate. The formation of nanotubes over the whole surface of the Ti substrate was confirmed by FE-SEM (Fig. $2 \mathrm{~b}$ and c). Common to almost all anodic approaches, the side walls of the tubes exhibited irregularities, resulting in some moderate thickness variations (ripples), which is typical of low viscosity electrolytes containing glycerol. ${ }^{15,19}$ This thin sheet of nanotubes can potentially act simultaneously as both an active material and a current collector.

Fig. 2d shows the FE-SEM micrograph of nanocrystalline $\mathrm{TiO}_{2}$ powders annealed at $780^{\circ} \mathrm{C}$ for $1 \mathrm{~h}$. As it can be seen, the sample consists of a fairly fine distribution of spherical-like particles with an average particle size in the range of 30-60 $\mathrm{nm}$. Good agreement was found between the particle size in FE-SEM micrographs and the calculated results for the crystallite size, which means particles mostly consisted of single crystallites. In terms of morphology, the spherical-like particles obtained here are of interest: First, the spherical shape results in higher surface contact between the material and the electrolyte, which consequently leads to the enhancement of the electrochemical activity and second, this morphology contributes to the higher packing density, subsequently resulting in higher volumetric energy density. ${ }^{20}$ Finally, the nanoscale dimension of the particles results in an increase in the total stored charge, which includes both double layer and pseudocapacitive effects. ${ }^{21}$ However, particular attention must be paid to further processing of nano-sized powders into active films because in most cases, they tend to re-agglomerate into large size grains. An alternative way to produce porous films is by growing nanotubes, as has been shown in this paper, or nanorods, which eases the access to the active material.

In general, the $\mathrm{CV}$ method is used to characterize the capacitive behaviour of the electrode materials. The CV curve of an ideal electrochemical double layer capacitor shows the characteristics of a rectangular mirror image with respect to the zero-current line. ${ }^{15}$ Although some area normalized capacitance values as high as $90-120 \mu \mathrm{F} \mathrm{cm} \mathrm{cm}^{-2}$ have been reported for anatase nanoparticles, suggesting the pseudocapacitive contribution to the electrochemical energy storage, ${ }^{21}$ based on the literature, titania would contribute a non-faradic capacitance, with a very low specific capacitance. ${ }^{16,22,23}$

Fig. 3a shows a comparison of the overlaid $\mathrm{CVs}$ of the $\mathrm{TiO}_{2} / \mathrm{NT}$ and $\mathrm{TiO}_{2} /$ powder at the scan rate of $100 \mathrm{mV} \mathrm{s}^{-1}$. The $\mathrm{CV}$ curves for both working electrodes exhibited an almost rectangular shape, indicating good charge propagation within the electrodes and therefore good capacitive behaviour of the electrodes based on the non-faradic mechanism. In addition, the relatively linear increase of the current density with increasing scan rate (Fig. 3b) demonstrates that the charge is primarily non-faradic in nature and the contribution of the faradic part might be very little, if it exists at all. ${ }^{24}$

The calculated specific capacitance of both working electrodes is plotted against the scan rate as shown in Fig. 3c. As it is evident, the capacitance values of the $\mathrm{TiO}_{2} / \mathrm{NT}$ and $\mathrm{TiO}_{2} /$ powder are in the range of $538-911 \mu \mathrm{F} \mathrm{cm} \mathrm{cm}^{-2}$ and $33-181 \mu \mathrm{F} \mathrm{cm}^{-2}$, respectively, as the applied scan rate is decreased from $100 \mathrm{mV} \mathrm{s}^{-1}$ to $1 \mathrm{mV} \mathrm{s}^{-1}$. 

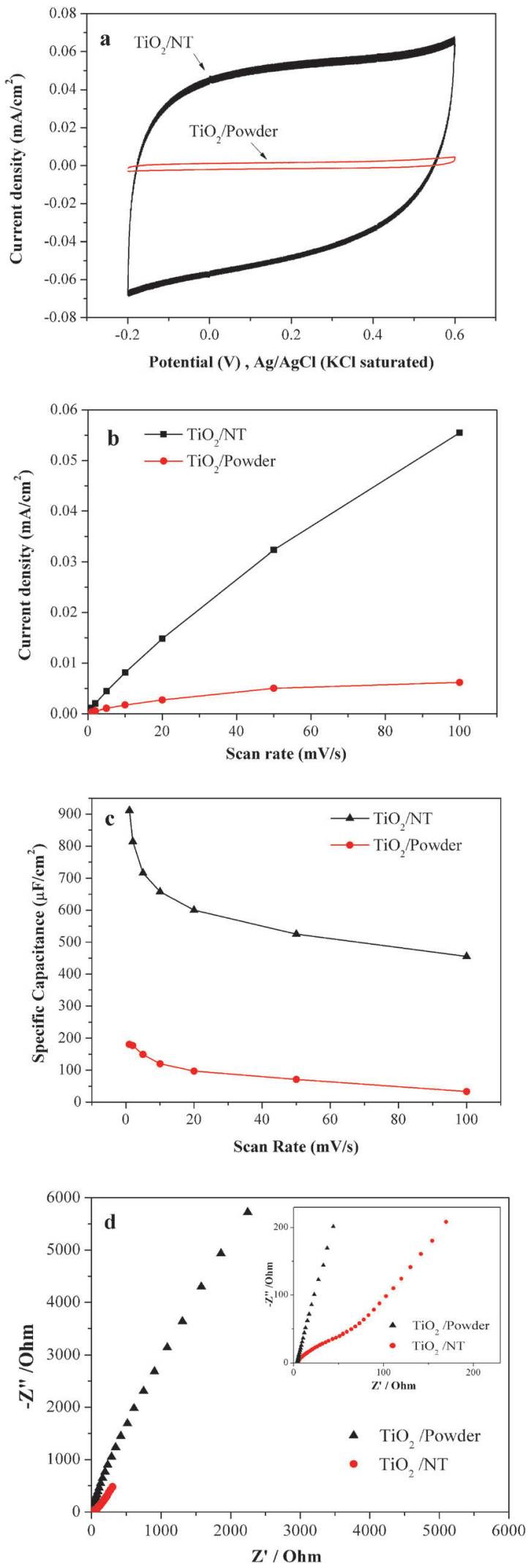

Fig. 3 (a) Overlaid $\mathrm{CV}$ curves in $1 \mathrm{M} \mathrm{KCl}$ at the scan rate of $100 \mathrm{mV} \mathrm{s}^{-1}$, (b) current density vs. scan rate, (c) calculated specific capacitance at different scan rates and (d) Nyquist plots of $\mathrm{TiO}_{2} / \mathrm{NT}$ and nanocrystalline $\mathrm{TiO}_{2}$ /powder. The inset in (d) shows the high frequency part of the Nyquist plots.
According to the obtained results, the specific capacitance of the titania nanotube electrode is higher than that of the powder counterpart. In addition, the obtained values for both types are several times higher than the values reported for the conventional double layer supercapacitors. ${ }^{25}$

It is well known that high surface area and interconnectivity of the active materials will enhance the capacitive properties. ${ }^{26}$ The advantage of $\mathrm{TiO}_{2}$ nanotube layers produced by electrochemical anodization is that they are suitably back-contacted to the titanium substrate and form an oriented, aligned and perpendicular structure to the substrate, which offers greatly improved electron transfer pathways compared to non-oriented (powder) structures. ${ }^{17}$ It is well known that high conductivity of the active materials will enhance capacitance properties. $^{27}$ The higher conductivity can be further investigated in terms of geometrical aspects. Highly ordered nanotube arrays can be viewed as nanostructures with direct pathways for electron transfer, which greatly reduces the disturbance from interparticle connections, offering the possibility that the initially low conductivity of titania structures can be overcome. Moreover, as proposed in the literature, these channels, as a form of open porosity, facilitate the ionic mass transfer through mesopores by providing pathways through which the dynamic sheath of solvent molecules, the solvation shell, can easily pass. The higher ionic mass transfer consequently results in higher capacitance values. Therefore, it can be concluded that these oriented self-organized $\mathrm{TiO}_{2}$ nanotube arrays exhibit great potential as electrochemical supercapacitor electrodes.

Fig. 3d shows typical Nyquist plots of the two types of titania. The high frequency regions of the spectra are shown as the inset in Fig. 3d. Polycrystalline titania samples usually show a distinct or overlapping semicircular arc corresponding to bulk and grain boundary responses, which corresponds to the charge transfer limiting process and is ascribed to the double layer capacitance $\left(C_{\mathrm{d} 1}\right)$ in parallel with the charge transfer resistance $\left(R_{\mathrm{ct}}\right)$ at the contact interface between the electrode and the electrolyte solution. However, as it is vividly shown in the inset in Fig. 3d, no semicircle was observed in either sample, indicating that the charge transfer of these working electrodes is good enough to be used for supercapacitor applications and there is virtually no indication of electrical resistance. In addition, the slope in nanocrystalline $\mathrm{TiO}_{2} /$ powder remains constant, whereas the slope in $\mathrm{TiO}_{2} / \mathrm{NT}$ increases in low frequency, representative of the ion diffusion in the structure of the electrode indicating a pure capacitive behaviour. The slope of the curve in the low frequency region is called the Warburg resistance and is a result of the frequency dependence of ion diffusion in the electrolyte to the electrode interface. These remarkable results demonstrate the exciting commercial potential for high performance, environmental friendly and low-cost electrical energy storage devices based on this new type of material.

Two types of titania nanostructures: titania nanotube arrays and nanocrystalline $\mathrm{TiO}_{2} /$ powder were fabricated through different routes for electrochemical supercapacitor applications. Both electrodes demonstrated exceptionally high values compared with the conventional titania used in supercapacitor applications. Moreover, the highly ordered titania nanotube 
arrays exhibited distinct advantages, such as providing rigid tubular channel paths and highly active surface sites for ion diffusion and charge transfer, which provide capacitance values (538-911 $\mu \mathrm{F} \mathrm{cm}^{-2}$ ) several times higher than those of conventional double layer capacitors.

\section{Acknowledgements}

Financial support from the University of Wollongong and the Australian Research Council (ARC, grant No. DP1093952) are gratefully acknowledged. The authors would like to thank Dr Tania Silver for critical reading of the manuscript and Alfred T. Chidembo for valuable discussions.

\section{Notes and references}

1 J. Qiu, W. Yu, X. Gao and X. Li, J. Sol-Gel Sci. Technol., 2007, 44, 235-239.

2 J. R. Jennings, A. Ghicov, L. M. Peter, P. Schmuki and A. B. Walker, J. Am. Chem. Soc., 2008, 130, 13364-13372.

3 T. Stergiopoulos, A. Ghicov, V. Likodimos, D. S. Tsoukleris, J. Kunze, P. Schmuki and P. Falaras, Nanotechnology, 2008, 19, 235602.

4 S. K. Mohapatra, K. S. Raja, V. K. Mahajan and M. Misra, J. Phys. Chem. C, 2008, 112, 11007-11012.

5 M. Salari, M. Rezaee, S. P. H. Marashi and S. H. Aboutalebi, Powder Technol., 2009, 192, 54-57.

6 A. Mohammadpour and K. Shankar, J. Mater. Chem., 2010, 20, 8474-8477.

7 J. M. Macak, S. P. Albu and P. Schmuki, Phys. Status Solidi RRL, 2007, 1, 181-183.

8 J. M. Macak, P. J. Barczuk, H. Tsuchiya, M. Z. Nowakowska, A. Ghicov, M. Chojak, S. Bauer, S. Virtanen, P. J. Kulesza and P. Schmuki, Electrochem. Commun., 2005, 7, 1417-1422.

9 J. M. Macak, B. G. Gong, M. Hueppe and P. Schmuki, Adv. Mater., 2007, 19, 3027-3031.
10 J. M. Macak and P. Schmuki, Electrochim. Acta, 2006, 52, $1258-1264$.

11 W. Wei, S. Berger, C. Hauser, K. Meyer, M. Yang and P. Schmuki, Electrochem. Commun., 2010, 12, 1184-1186.

12 J. M. Macák, H. Tsuchiya and P. Schmuki, Angew. Chem., Int. Ed., 2005, 44, 2100-2102.

13 J. M. Macak, F. Schmidt-Stein and P. Schmuki, Electrochem. Commun., 2007, 9, 1783-1787.

14 F. Fabregat-Santiago, H. Randriamahazaka, A. Zaban, J. Garcia-Canadas, G. Garcia-Belmontea and J. Bisquerta, Phys. Chem. Chem. Phys., 2006, 8, 1827-1833.

15 H.-T. Fang, M. Liu, D. W. Wang, T. Sun, D. S. Guan, F. Li, J. Zhou, T. K. Sham and H. M. Cheng, Nanotechnology, 2009, 20, 225701.

16 Y. Xie, L. Zhou, C. Huang, H. Huang and J. Lu, Electrochim. Acta, 2008, 53, 3643-3649.

17 N. K. Shrestha, Y.-C. Nah, H. Tsuchiya and P. Schmuki, Chem. Commun., 2009, 2008-2010.

18 R. A. Spurr, Anal. Chem., 1957, 29, 760-762.

19 J. M. Macak, H. Tsuchiya, L. Taveira, S. Aldabergerova and P. Schmuki, Angew. Chem., Int. Ed., 2005, 44, 7463-7465.

20 D. Dambournet, I. Belharouak and K. Amine, Chem. Mater., 2009, 22, 1173-1179.

21 J. Wang, J. Polleux, J. Lim and B. Dunn, J. Phys. Chem. C, 2007, 111, 14925-14931.

22 T. Brezesinski, J. Wang, S. Tolbert and B. Dunn, J. Sol-Gel Sci. Technol., 2010, 1-6.

23 B. E. Conway and W. G. Pell, J. Solid State Electrochem., 2003, 7, 637-644.

24 M. D. Stoller, S. Park, Y. Zhu, J. An and R. S. Ruoff, Nano Lett., 2008, 8, 3498-3502.

25 Y. Zhang, H. Feng, X. Wu, L. Wang, A. Zhang, T. Xia, H. Dong, X. Li and L. Zhang, Int. J. Hydrogen Energy, 2009, 34, 4889-4899.

26 B. Xu, F. Wu, R. Chen, G. Cao, S. Chen, Z. Zhou and Y. Yang, Electrochem. Commun., 2008, 10, 795-797.

27 F. Fabregat-Santiago, E. M. Barea, J. Bisquert, G. K. Mor, K. Shankar and C. A. Grimes, J. Am. Chem. Soc., 2008, 130, 11312-11316. 